\section{Um estude de capital social gerado a partir de Redes Sociais no Orkut e nos Weblogs}

\section{RESUMO}

0 presente artigo parte de uma reconstrução dos conceitos de capital social, dentro de uma abordagem de rede social, buscando compreender como o mesmo é encontrado em comunidades do Orkut e dos weblogs. Através de um estudo de caso, procura-se compreender como as interações sociais podem auxiliar a constituir diferentes formas de capital social e como essas formas podem trazer à tona aspectos relevantes no estudo de grupos na Internet.

\section{ABSTRACT}

The following paper starts from a reconstruction of social capital concepts connected with the social network approach. By doing this reconstruction, we try to understand how social capital can be found in Orkut and weblogs communities. Through a case study, we show how social interactions can help build different forms of social capital and how these forms can show important aspects of the study of those groups in the Internet.

\section{PALAVRAS-CHAVE (KEY WORDS)}

- Weblogs (weblogs)

- Orkut (orkut)

- Capital social (social capital)

\section{Raquel da Cunha Recuero}

Doutoranda pelo PPGCOM/UFRGS e professora da ECOS/UCPEL.

\section{Introdução}

O presente trabalho visa verificar que tipo de capital social é gerado em redes sociais na Internet, tomando como estudo de caso três comunidades do Orkut e uma rede de blogs, observados ao longo do ano de 2004. Através da abordagem de rede social, buscou-se reconstruir conceitos básicos, como o de laço, interação e relação social, tentando compreender como esses conceitos relacionam-se com a produção de capital social e como esta pode ser verificada nos grupos selecionados. Ao final, é discutida a importância da interação, bem como do sistema de comunicação mediada por computador, para que as redes sociais possam tornar-se densas e produzir mais capital. Trata-se de um estudo exploratório, que não tem a pretensão de generalização, mas, unicamente, de contribuir para o debate em torno da sociabilidade no ciberespaço.

\section{A Abordagem de redes sociais' e $\bullet$ capital social}

Uma rede social é definida como um conjunto de dois elementos: atores (pessoas, instituições ou grupos) e suas conexões (Wasserman e Faust, 1994, Degenne e Forsé, 1999). Trata-se, assim, de uma abordagem focada na estrutura social, na qual "individuals cannot be studied independently of their relations to others, nor can dyads be isolated from their affiliated structures"2 (Degenne e Forsé, 1999, p. 3). A abordagem de rede é importante porque enfatiza as conexões en- 
tre os indivíduos no ciberespaço ( Garton, Haythornthwaite e Wellman, 1997, p. 1).

A conexão apresentada entre dois atores em uma rede social é denominada laço social, de acordo com Wasserman e Faust (1994, p. 18), ou seja, aquilo que "establishes a linkage between a pair of actors" 3 . Um laço é composto por relações sociais, que por sua vez, são constituídas por interações sociais ${ }^{4}$. Uma interação social é aquela ação que tem um reflexo comunicativo entre o indivíduo e seus pares. Trata-se de uma manifestação de caráter comunicativo (Watzlavick, Beavin e Jackson, 2000, p. 18), com reflexo social. Essas interações repetidas constituem relações sociais.

O conceito de laço social desenvolvido até agora passa pela idéia de interação social. É um laço social constituído a partir dessas interações e relações, sendo denominado laço relacional. Entretanto, Breiger (1974, pp. 183-185) explica que o laço social pode ser constituído de outra forma: através de associação, ou seja, uma conexão entre um indivíduo e uma instituição ou grupo, representada unicamente por um sentimento de pertencimento. Trata-se de um laço associativo. Para o autor, portanto, o laço social não depende apenas de interação. Laços relacionais, portanto, são aqueles constituídos através de relações sociais, e apenas podem acontecer através da interação entre os vários atores de uma rede social. Laços de associação, por outro lado, independem dessa ação, sendo necessário, unicamente, um pertencimento a um determinado local, instituição ou grupo. Neste trabalho, entenderemos os laços associativos como meras conexões formais, que independem de ato de vontade do indivíduo, bem como de investimento. Neste sentido, não interferem na estrutura social, tratando-se, simplesmente, de uma classificação. Por conta disso, esses laços não serão considerados sociais, mas serão levados em conta por sua característica formal de agregação.

Os laços sociais também podem ser fortes e fracos. De acordo com Granovetter
(1973, p. 1361), "the strength of a tie is a (probably linear) combination of the amount of time, the emotional intensity, the intimacy (mutual confiding) and the reciprocal services which characterize the tie ${ }^{\prime \prime}$. Laços fortes são aqueles que se caracterizam pela intimidade, pela proximidade e pela intencionalidade em criar e manter uma conexão entre duas pessoas. Os laços fracos, por outro lado, caracterizam-se por relações esparsas, que não traduzem proximidade e intimidade. Laços fortes constituem-se em vias mais amplas e concretas para as trocas sociais (Wellman, 1997), enquanto os fracos possuem trocas mais difusas ${ }^{6}$.

\section{Capital Social}

O capital social, de acordo com Putnam (2000, p. 19), "refers to connection among individuals - social networks and the norms of reciprocity and trustwothiness that arise from them"7.

Bourdieu também estabelece uma definição de capital social:

social capital is the aggregate of the actual and potential resources which are linked to possession of a durable network of more or less institucionalized relationships of mutual acquaintance and recognition - in other words, to membership of a group - which provides each of the members with the backing of the collectivity-owned capital(...) (1983, pp. 248-249) ${ }^{8}$.

Para o autor ${ }^{9}$, o capital social é relacionado, a um determinado grupo (rede social). O capital social, para Bourdieu, não se encontra nos indivíduos, mas ao contrário, encontra-se embutido nas relações sociais das pessoas.

Putnam (2000) e Bourdieu (1983) têm dois conceitos diferenciados. Para Putnam, o capital é um conjunto de recursos possuído pelo grupo enquanto, para Bourdieu, 
ele é uma conseqüência das relações sociais, que é percebida pelos envolvidos in abstracto (e que é, deste modo, passível de ser transformado por eles em outra forma de capital). O conceito de Bourdieu é muitas vezes criticado por ter um caráter individualista, a partir do momento em que se foca na capacidade de um indivíduo em contribuir e utilizar os recursos coletivos para seus próprios fins, através da transformação desse capital em outro (Flora, 1998, pp. 282-284). Trata-se de um conceito de fundo marxista, influenciado pela divisão de classes e pelo capital em si. Putnam acredita que o capital social pode ser possuído tanto pelos indivíduos quanto pelo grupo, já levando em conta as relações entre o grupo para a produção desses recursos (reciprocidade e confiança).

Bertolini e Bravo (2004) trabalham com o capital social a partir de uma perspectiva de recursos dos quais dispõe um grupo de indivíduos, representados por aspectos específicos da estrutura social que os auxiliam a atingir objetivos e interesses. Gyarmati e Kyte (2004, p. 3) têm idéia semelhante e explicam que o capital social constitui-se no conteúdo das relações sociais em uma rede. É neste sentido que também entendemos este capital: trata-se do conteúdo embutido nas interações que constituem os laços sociais, que pode ser acumulado, aprofundando um determinado laço e aumentando o sentimento de grupo.

O capital social tem, deste modo, dupla faceta: coletivo e individual. Diz respeito ao indivíduo, a partir do momento em que este é que pode alocar esses recursos e utilizá-los. É coletivo, porque faz parte das relações de um determinado grupo ou rede social e somente existe com ele. O capital social, portanto, apenas existe enquanto recurso coletivo, mas, por ter capacidade de ser alocado e utilizado individualmente, tem este caráter duplo.

O capital social depende ainda de investimento dos indivíduos. Isso porque "the network of relationships is the product of investment strategies, individual or collective, consciously or unconsciously, aimed at establishing or reproducing social relationships that are directly usable in the short or long term $(\text {... })^{\prime 10}$ (Bourdieu, 1983, p. 249). Como uma relação social que constitui a forma de produção do capital e existe através de investimento e custo para os envolvidos, o capital social, que transita e é produzido através dela, também depende desses investimentos para que possa ser acumulado nos laços sociais (Gyarmati e Kyte, 2004, p. 3). Sem investimento, os laços sociais tendem a enfraquecer com o tempo, depreciando o capital social de um determinado grupo. Bourdieu explica que a reprodução do capital social também exige um esforço de sociabilidade, ou seja, de dispêndio de tempo e energia e de outras formas de capital de modo indireto (por exemplo, capital econômico) (1983, p. 250). Além disso, o capital social também depende da capacidade de interação (e interesse) dos indivíduos envolvidos: "individual connections in a social network can also vary in their ability to accumulate social capital based on how well the individuals interact"11 (Gyarmati e Kyte, 2004, p. 2).

Deste modo, o capital social constituise em um conjunto de recursos de um determinado grupo, obtido através da comunhão dos recursos individuais, que pode ser usufruido por todos os membros do grupo, e que está baseado na reciprocidade. Ele está embutido nas relações sociais (como explica Bourdieu,1983) e baseia-se no conteúdo delas (Gyarmati e Kyte, 2004; Bertolini e Bravo, 2004). Portanto, para que se estude o capital social dessas redes, é preciso estudar não apenas suas relações, mas igualmente, o conteúdo que provém delas.

Mas como se apresenta o capital social? Bertolini e Bravo (2004, pp. 1-5) partem da definição de Coleman (1988), que explica que o capital social é heterogêneo, e constroem categorias que constituiriam aspectos nos quais o capital social pode ser encontrado. Essas categorias seriam: a) re- 
lacional - que compreenderia a soma das relações, laços e trocas que conectam os indivíduos de uma determinada rede; b) normativo - que compreenderia as normas de comportamento de um determinado grupo e os valores deste grupo; c) cognitivo - que compreenderia a soma do conhecimento e das informações colocadas em comum por um determinado grupo; d) confiança no ambiente social - que compreenderia a confiança no comportamento de indivíduos em um determinado ambiente; e) institucional - que incluiria as instituições formais e informais, que constituem-se na estruturação geral dos grupos, onde é possível conhecer as "regras" da interação social e o nível de cooperação e coordenação é bastante alto.

Tais aspectos do capital social seriam divididos entre os aspectos de grupo (que eles também chamam de segundo nível de capital social), ou seja, aqueles que apenas podem ser desfrutados pela coletividade, como a confiança no ambiente social $(d)$ e a presença das instituições (e), e os aspectos individuais, como as relações (a), as leis ou normas (b) e o conhecimento (c), que variam de acordo com os indivíduos (primeiro nível de capital social). A existência de capital social de primeiro nível é requisito para a constituição do capital de segundo nível (que representa uma sedimentação do primeiro) (Bertolini e Bravo, 2004, pp. 510). Deste modo, um segundo nível de capital demonstra uma maior maturidade da rede social, além de maior densidade e existência no tempo de seus laços. $\mathrm{O}$ capital de segundo nível é importantíssimo, porque aumenta a qualidade e a produção do de primeiro nível, criando um círculo de produção constante de recursos pelo grupo.

Uma vez discutidos os aspectos e as definições de capital social, passamos agora à discussão do capital social gerado pelas redes sociais na Internet, a partir de dois estudos de caso, em duas ferramentas de comunicação mediada por computador: o Orkut e uma rede de weblogs. O Orkut, enquanto sistema, vem sendo observado sistematicamente desde fevereiro de 2004, e desde abril, através da comunidade "Pesquisa em Comunicação" e "Eu Odeio Segunda-Feira". A comunidade "Ciberidea" foi acrescentada à pesquisa em julho do mesmo ano. Já o grupo de blogueiros em questão é acompanhado pela pesquisa desde 2002, com trabalhos anteriores (Recuero, 2002 e 2003).

\section{- capital social nas redes sociais no Orkut}

O Orkut ${ }^{12}$ é um software social que alcançou grande popularidade entre os internautas brasileiros. Criado em janeiro de 2004, por Orkut Buyukkokten (Recuero, 2004), o sistema apenas permite a entrada de quem foi convidado por alguém já cadastrado nele. O Orkut funciona basicamente através de perfis e comunidades. Os perfis são criados pelas pessoas ao se cadastrar, que indicam também quem são seus amigos. As comunidades ${ }^{13}$ são criadas pelos indivíduos e podem agregar grupos, funcionando como fóruns, com tópicos (nova pasta de assunto) e mensagens (que ficam dentro da pasta do assunto).

O Orkut é um sistema que proporciona duas formas de interação social mediada por computador: a interação mútua (Primo, 1998 e 2003 $)^{14}$, que pode ser observada nos posts das comunidades (em estilo de fórum), onde cada um pode escrever o que deseja e receber manifestações em retorno; bem como nos scrapbooks dos perfis (uma espécie de caderno de notas, onde é possível deixar recados para os amigos e receber deles recados) e testemunhos; além de mensagens enviadas para uma comunidade ou para alguém em particular (existia inicialmente a opção de envio para os "amigos dos amigos" que foi desabilitada devido ao grande número de spam no sistema). A interação reativa (Primo, 1998 e 2003) pode ser considerada social quando alguém solicita a outrem que seja seu amigo (pedido de amizade), pedido este que pode ser aceito ou negado unicamente; nas 
classificações que podem ser dadas aos amigos (sob a forma de concessão de estrelas, corações e gelos no sentido de "classificar" o amigo - denomina-se karma, no sistema - como legal, sexy, confiável e, até mesmo, declarar-se fã do amigo em questão); bem como classificar o indivíduo como "amigo", "conhecido", "não conhecido ainda", "melhor amigo"; e, por fim, no âmbito das comunidades moderadas, quando alguém solicita a entrada e o moderador aceita ou não. Trata-se de reação porque a ação, embora com reflexos sociais, constitui-se unicamente em um apertar de botões, sem que a outra parte possa manifestar-se a este respeito.

Para fins desse artigo, foram estudadas três comunidades do Orkut, de tamanhos diferentes. $\mathrm{O}$ objetivo é perceber que tipo de relações e laços sociais podem ser construídos através do sistema e que tipo de capital social é produzido através das interações nestes espaços. Deste modo, ao final, será possível traçar algumas premissas sobre como essas formas de interação podem influenciar esse capital e a própria constituição da rede social.

\section{Pesquisa em Comunicação}

A comunidade "Pesquisa em Comunicação"15 (2150 membros em 05 de janeiro de 2005) é uma comunidade pequena em relação às maiores comunidades brasileiras do Orkut. Foi criada em abril de 2004 pela autora (que é também a moderadora) e tratase de uma comunidade pública (qualquer um pode entrar) e não anônima (não são permitidas manifestações em anonimato). Entretanto, muito pouca interação acontece no seu meio. De sua fundação até dezembro de 2005, por exemplo, foram enviadas aproximadamente 733 mensagens ${ }^{16}$, divididas entre 201 tópicos, em uma média de 3,64 mensagens por tópico. Ou seja, se cada membro da comunidade escreveu apenas uma mensagem durante todo o período de existência da comunidade, teríamos que mais da metade deles (1417 membros, $65,9 \%$ ) jamais participou das discussões. Se, entretanto, levarmos em conta que uma grande parcela dessas 733 mensagens foram feitas, muitas vezes, pela mesma pessoa (apenas para dar um exemplo, o tópico "Esta é uma comunidade?"17 teve nove mensagens, duas da mesma pessoa), a participação dos membros na comunidade é ainda menor. A maior parte dos tópicos da comunidade possui poucas respostas (menos de quatro, como se depreende pela média geral), a maioria feita por pessoas diferentes. Além disso, tópicos como "apresentações"18 em que cada membro deu uma breve descrição de si são os que aumentam a média, com 131 mensagens. Essa falta de interação resulta em laços sociais fracos entre os membros, que acabam perdendo o próprio senso de grupo e de comunidade. Um exemplo disso é que, recentemente, a comunidade sofreu um ataque ${ }^{19}$ de um membro do grupo dos chamados "Semeadores da Discórdia", no qual um indivíduo manifestou-se de maneira agressiva, dizendo que a pesquisa era uma bobagem.

Pesquisa não serve pra nada $12 / 17$ / 2004 3:14 PM

Meu nome ta feito seus fudido, não preciso de fazer pesquisinha de merda se eu encontro com vcs na rua, encho a cara de cada um! ${ }^{20}$

O comentário passou vários dias sendo ignorado pelos membros da comunidade, até que dois membros manifestaram-se solicitando o apagamento do mesmo, por sentirem-se agredidos. Ora, dos mais de dois mil membros da comunidade, apenas dois defenderam a comunidade após o ataque. O exemplo reforça a falta de sentido de grupo, considerado característico das redes sociais mais densas, como uma comunidade (Weber, 1987; Tönies, 1985; Wellman 1997). Neste ambiente, o capital social observado nas interações pôde ser classificado em:

a) Informação (cognitivo) - A informação é, 
eventualmente, colocada em comum. Apesar da grande maioria dos pedidos de ajuda com trabalhos e pesquisas ser sumariamente ignorada pela comunidade, tópicos que possibilitam a discussão (como o tópico "esta é uma comunidade? "21, que, até o dia nove de janeiro, tinha onze posts, quase quatro vezes a média geral da comunidade) tendem a ter mais participação e debate. Entretanto, praticamente todos os tópicos solicitando ajuda com relação a temas de pesquisa, dicas de bibliografia ou mesmo informações sobre pesquisa não são respondidos pelos membros mais aptos. Alguns, inclusive, enviaram mensagem ao moderador reclamando da quantidade de pedidos de ajuda, já que o objetivo da comunidade, alegavam, era debater temas de pesquisa e não auxiliar alunos da graduação com suas dúvidas. Logo, o capital de informação presente na comunidade não é facilmente acessível pelos membros, pois as pessoas que detêm o conhecimento sobre os assuntos discutidos sentem-se ressabiadas e irritadas para colocar o que sabem em comum. O tópico abaixo, por exemplo, está desde o dia 16/12/2004 sem receber resposta.

\section{Ajuda para TCC!!! 12/16/2004 6:18 PM}

Vi que só tem feras por aqui, então vou pedir SOCORRO: quero dicas para meu tcc, que é sobre como a história é tratada pela produções televisivas e filmes Agradeço muuuuuito as dicas. Beijo a todos! ${ }^{22}$

Entretanto, algumas informações circulam com maior facilidade. Tópicos informando sobre assuntos pertinentes à comunidade, como o portal de periódicos da CAPES, participação em congressos e revistas científicas, que não exigem, necessariamente, uma interação, mas que são colocados em comum gratuitamente acrescem capital de conhecimento a essa comunidade.

\section{b) Possibilidade de relacionar-se com pes-}

soas de mesmos interesses (relacional) Um aspecto que parece ser importante é a possibilidade de conhecer mais pessoas com interesses em comum. O tópico de apresentações dos membros da comunidade é o que tem maior número de participação dos membros da comunidade (131 posts até o dia cinco de janeiro de 2005). Isso demonstra que existe um interesse em conhecer e dar-se a conhecer. A possibilidade de associar-se à comunidade para conhecer pessoas que tenham interesses de pesquisa semelhante faz com que esse potencial, que é também um recurso da comunidade, seja importante. Muitos, inclusive, declaram este interesse na apresentação.

A "Pesquisa em Comunicação" é portanto uma comunidade que possui mais laços associativos (já que a maioria de seus membros não interage dentro da comunidade, resultando em um reduzido sentido de grupo), mas que, ainda assim, através do sistema, que proporciona uma conexão sem desgaste entre os membros (uma conexão que, socialmente, não tem custo) consegue manter algum capital social, embora unicamente de primeiro nível.

\section{Ciberidea $^{23}$}

A comunidade "Ciberidea" foi fundada em julho de 2004, com o objetivo de tornar-se uma comunidade que representasse o grupo de pesquisa de mesmo nome. Trata-se de uma comunidade moderada (é preciso ser convidado ou autorizado pelo moderador para entrar), que permite a participação de pessoas de modo anônimo. Tem 131 participantes ${ }^{24}$, todos interessados ou atuantes na área da pesquisa em comunicação.

Inicialmente, é preciso perceber que trata-se de uma comunidade substancialmente menor que a "Pesquisa em comunicação" (131 contra mais de dois mil membros). Além disso, a "Ciberidea" tem um forte fundamento em laços sociais pré-existentes (já que o grupo de pesquisa que lhe empresta o nome atua e se conhece no es- 
paço concreto, embora isso não aconteça com todos os seus membros no Orkut), o que não acontece com a "Pesquisa em Comunicação". É também uma comunidade moderada (a associação precisa ser autorizada), o que indica que aqueles que pertencem a ela já possuem algum laço, se não entre si, ao menos com o moderador, enquanto a "Pesquisa" é livre para quem desejar associar-se. Um outro fator importante é a destacada atuação do moderador, que sempre responde os tópicos iniciados e manifesta-se de forma a convidar os demais participantes a responder.

\section{E aí Rico? 7/30/2004 12:14 AM}

Desanimou? Fala mais um pouco pra nós como vc está vendo essa questão. Pega aquilo q tá te interessando e desenvolve um pouco mais. Não precisa ser muito genérico, pode falar de casos e exemplos q te chamam a atenção. ${ }^{25}$

No exemplo acima, percebe-se a atuação do moderador, que estimula e convida ao diálogo o autor de um tópico que passou sem comentários por quinze dias. Imediatamente após essa manifestação, várias pessoas da comunidade começaram a debater o assunto proposto pelo autor [Rico].

A interação social na "Ciberidea" dáse de maneira mais ampla. A comunidade tem um total aproximado de 48 tópicos, com 620 mensagens ${ }^{26}$, ou seja, uma média de 12,91 mensagens por tópico. Trata-se, evidentemente, de uma participação bem maior do que na "Pesquisa em Comunicação". Além disso, a proximidade dos membros (já que muitos se conhecem também fora da comunidade) é evidente em várias mensagens. A "Ciberidea" tem maior quantidade de interação social e relações sociais, apontando, como conseqüência, a existência de laços sociais mais fortes do que na "Pesquisa em Comunicação". Entretanto, talvez esse aprofundamento dê-se nesta comunidade porque seus laços são mais multiplexos (possuem uma quantidade de relações sociais mais variada, já que os seus membros atuam em vários virtual settlements ${ }^{27}$, já que, como foi explicado, muitos membros atuam também no grupo de pesquisa). Essa qualificação do laço social reflete-se também na qualidade do capital social encontrado.

a) Informação (cognitivo) - $\mathrm{O}$ acesso à informação se dá de maneira mais fácil na "Ciberidea". É possível obter informações de qualidade e debates interessantes. Tópicos que contêm debates sobre aspectos diversos da cibercultura, bem como dicas de artigos e leituras, são comuns e têm grande participação. Ao contrário da "Pesquisa em Comunicação", tópicos solicitando ajuda são rapidamente respondidos e discutidos. Além disso, a expressiva maioria dos tópicos trabalha com discussão, debate e informações, e relaciona-se com essa forma de capital social.

b) Possibilidade de relacionar-se com pessoas de mesmos interesses (relacional)Apesar de ser uma riqueza óbvia para uma comunidade de pesquisadores, a "Ciberidea" não parece ter uma concentração muito grande de capital nesse sentido. A maioria das pessoas não se preocupa em dar-se a conhecer ou mesmo de estabelecer relações sociais com desconhecidos, o que é muito mais comum na "Pesquisa em Comunicação".

A "Ciberidea", talvez por ser uma comunidade pequena e moderada, o que aumenta a possibilidade de laços mais fortes entre seus associados, é uma comunidade com uma grande quantidade de capital social voltado para o conhecimento e a informação. Em comparação com a "Pesquisa em Comunicação", tratam-se de recursos mais ricos e mais profundos e, sobretudo, colocados em comum mais facilmente. Isso pode se dar porque a comunidade não é pública, ou seja, seus membros são selecionados pelo moderador, ou pela possível pré-existência de laços relacionais anteriores ao Orkut. Encontram-se, portanto, laços fundamentalmente relacionais, embora a 
existência de laços associativos possa ser emergente a partir do grupo no espaço concreto. Outros recursos, como a possibilidade de complexificar as redes individuais, também podem ser utilizados, embora não apareçam com força nas interações. A comunidade mantém, assim, um capital social principalmente cognitivo de primeiro nível $^{28}$.

\section{Eu odeio Segunda-Feira ${ }^{29}$}

A comunidade "Eu odeio Segunda-Feira" é uma das maiores comunidades do Orkut. Tem hoje $95.657^{30}$ membros, trata-se de uma comunidade pública que permite que seus usuários manifestem-se de forma anônima. A comunidade foi criada em abril de 2004 e tem 1714 tópicos abertos ${ }^{31}$ com aproximadamente 14.703 mensagens, com uma média de 8,57 mensagens por tópico. Entretanto, apesar da média alta, não é uma comunidade com grande interação. Essa média ocorre por causa da ocorrência de tópicos com um grande número de comentários (inclusive "supertópicos" com mais de 600 mensagens $^{32}$ ). Esses "supertópicos" são principalmente jogos com uma certa carga de sedução. São tópicos como "Dê uma nota para a pessoa acima" 33 (263 posts), onde os associados são convidados a avaliar o último comentarista do tópico; "No rosto ou na boca" 34 (636 posts), tópico que indica onde cada participante deveria ser beijado; ou mesmo o "Pé na bunda ou mão na bunda" (577 posts), indicando um possível relacionamento ou não com o último comentarista; ou mesmo o "Jogo Novo" ${ }^{\prime 35}$ (444 posts) com onde os participantes devem dizer se "correm, beijam ou levam pra casa" os demais.

BETH !!!! QUE BUNDINHA !!! 11/27/ 2004 2:42 AM

COM TODA CEEEERTEZA MÃO NA BUNDA, SÓ PARA LEMBRA SE VC QUISER MUITO MAIS QUE MÃO NA BUNDA !!!
É SÓ VC QUERER !!! ${ }^{6}$

11/29/2004 3:35 PM

Oiiii gatinha apesar de vc ter dois irmãos eu lhe daria um baita beijo na boca e chamaria seus manos de cunhado. beijuuusssssssss ${ }^{37}$

Os exemplos acima demonstram o quanto a característica da sedução está presente como motivação da interação dos participantes desses tópicos. Apenas esses quatro tópicos possuem 1920 comentários, ou seja, mais de $10 \%$ do total de mensagens da comunidade. Além disso, se levarmos em conta que cada associado, em todo o tempo de existência da comunidade, tenha manifestado-se, pelo menos uma única vez, temos, novamente que $15 \%$, apenas, utilizaram a comunidade como espaço de interação. Tão pouca interação demonstra a predominância de laços associativos dos indivíduos com o grupo. A grande maioria das pessoas associadas a essa comunidade não a utiliza como um espaço de interação.

a) Possibilidade de relacionar-se com pessoas de mesmos interesses (relacional) Novamente, o objetivo da comunidade, ou do grupo, parece ser apenas encontrar-se e poder conhecer-se. $\mathrm{O}$ aspecto da sedução é muito importante, pois os jogos que mais atraem a interação na comunidade são, justamente, os que permitem aos seus associados se darem a conhecer. Os jogos trabalham com classificação ("bonito/feio", "ficaria/não ficaria" e etc.) dos associados, como uma medida de sua capacidade de sedução ou de arrecadar amigos/interessados. O valor agregado do grupo é o mesmo de uma festa: quanto mais pessoas, maior a possibilidade de conhecer pessoas interessantes.

$\mathrm{O}$ acesso às informações, no caso da "Odeio Segunda-Feira" é extremamente complicado, pois basta que cinco pessoas abram novos tópicos para que outro tópico importante saia da lista sem, sequer, ter sido lido pelos demais associados. (A lista de tópicos que aparece na página inicial da 
comunidade tem sempre os últimos cinco tópicos mais comentados.) Logo, a informação que o grupo detém dificilmente será compartilhada e usufruída pelos membros. Além do mais, por ser uma comunidade muito grande e com uma grande variedade de tópicos, e pública, é comum que sofra ataques, como o dos "Multiplicadores" 38 , que acabam silenciando ou mesmo criando situações de dificuldade de participação dos membros, que precisam procurar, entre várias dezenas de tópicos de "flood", aquele no qual desejam participar. Levando-se em conta que o sistema do Orkut enfrenta problemas de tráfego, a dificuldade de acompanhar a interação é ainda aumentada. Além disso, muito daquilo que é produzido na comunidade, muitas vezes, é boato $^{39} \mathrm{e}$, por isso, as informações geram desconfiança e não são aproveitadas pelos membros da comunidade. Essa desconfiança demonstra a inexistência de laços de confiança.

Sobre essa quantidade de novos tópicos com poucas respostas, uma importante contribuição é fornecida pelo trabalho de Lilia Efimova (2005, p. 3) a respeito da "visibilidade social" em sistemas de fóruns. Para a autora, as pessoas competem pela atenção dos demais através da abertura de novos tópicos. Essa competição poderia ser entendida como uma forma de se sobressair e conquistar confiança e reputação junto aos demais membros, bem como uma possibilidade de maior número de "amigos". Essa visibilidade pode ter várias conseqüências, com o efeito "rich get richer" (Barabási, 2003), onde apenas aqueles indivíduos que já detêm alguma visibilidade terão suas mensagens respondidas, enquanto os demais continuarão sendo ignorados pelo grupo. A competição pela atenção e pelo ganho de "status" (confiança, reputação e atenção da comunidade), é visível tanto na participação das pessoas quanto na abertura de novos tópicos, mas acaba prejudicando a interação do grupo como um todo.

A comunidade "Eu odeio SegundaFeira", com pouca interação social entre os quase cem mil membros, possui uma prevalência de laços mais associativos, embora laços relacionais possam ser observados em alguns tópicos. Como a quantidade de novos tópicos é grande, devido à competição por visibilidade social (há dias em que a comunidade tem mais de 50 novos tópi$\cos )$, torna-se difícil que as pessoas consigam acompanhar o que é discutido. Por isso, muito pouca informação é difundida na comunidade. $\mathrm{O}$ capital social encontrado é fundamentalmente relacional. Não foi observado espírito de grupo ou cooperação coletiva, uma vez que a comunidade e seus membros também são atacados publicamente com freqüência, sem manifestações de suporte ou indignação dos demais.

O capital social constituído pelas comunidades do Orkut é associado a um nível, em geral, pequeno de interação social, o que se reflete nos laços sociais. Talvez por conseqüência da facilidade de associação a um grupo (já que trata-se de uma interação reativa), que não implica em custo (uma vez associado, o laço associativo se mantém sem a necessidade de interação, por tempo indefinido). Nas comunidades estudadas, o capital social constituído é fundamentalmente de primeiro nível, com alguma exceção da comunidade "Ciberidea", por conta das características especiais desta. Talvez o caso da "Ciberidea" demonstre que comunidades que surjam como espelho de comunidades offline ou com moderação possam ter mais sucesso na criação e sedimentação de capital social através da interação mediada. As demais comunidades, com espaço de interação apenas no Orkut, não conseguem ampliar o capital e criar e aprofundar os laços coletivos. Além disso, comunidades menores tendem a ter um capital de informação e conhecimento de maior qualidade, talvez porque a interação não seja tão caótica devido à visibilidade social. $\mathrm{O}$ grande capital agregado do sistema, entretanto, parece ser, principalmente, relacional, presente na possibilidade de conhecer pessoas e estabelecer novas relações. 
- Capital Social em Redes de Weblogs

As redes de weblogs (Recuero, 2002 e 2003) são compostas por blogueiros (e seus blogs, que funcionam como espaço de interação) que lêem-se uns aos outros e que interagem com alguma freqüência. Trata-se de uma rede social constituída através desses blogs, que atuam como uma representação do blogueiro, que interage através dele com outras pessoas.

Weblogs, de um modo geral, possuem ferramentas de troca muito populares: (a) ferramentas de comentários, que permitem que os leitores possam manifestar-se a respeito do que é discutido no blog; (b) blogrolls, que são as listas de blogs "recomendados" pelo blogueiro e (c) trackbacks, que são ferramentas que permitem que um post de algum blog que está sendo discutido em outro blog possa ser referenciado pelos dois. A única ferramenta que proporciona interação mútua (Primo, 1998 e 2003) são os comentários (Primo e Recuero, 2003), que permitem que qualquer um escreva o que quiser. Marlow (2004:3) considera essas ferramentas importantes através de um processo de leitura, escrita e referência e destaca a importância dos links neste contexto. Para ele, todo o processo social nas redes de blogs baseia-se nas trocas de hiperlinks. No entanto, o autor considera todos os links presentes em um blog como evidências de um laço social, o que nem sempre acontece (Primo e Recuero, 2003). Os links podem sim indicar a existência de relações e interações sociais, mas precisam ser analisados no tempo para que se verifique se são meras referências ou realmente produto de trocas comunicativas.

Para efeitos deste trabalho, utilizamos o grupo Blogueiros_Pel ${ }^{40}$, que já foi analisado anteriormente ${ }^{41}$ a respeito dos seus aspectos como grupo. O grupo, constituído de cerca de 35 blogs, existe há mais ou menos dois anos. Mas no que as interações sociais, em uma rede de blogs, diferenciamse das de uma comunidade no Orkut?

A primeira diferença que se percebe é que uma rede de weblogs é constituída basicamente de interações sociais. Ao contrário do Orkut, não existe um sistema formal que mantenha a comunidade mesmo quando os indivíduos não interagem nela. Portanto, os laços aqui são eminentemente relacionais, uma vez que dependem da interação social e do investimento. É necessário investir tempo e forças para interagir em uma ferramenta de comentários, e é preciso retornar para ver o que foi discutido em cima de uma opinião. Esse debate com outros blogueiros e com o próprio dono do blog gera laços sociais, que freqüentemente são traduzidos pela inclusão do blog do interagente no blogroll do blogueiro (como Marlow, 2004, indicou em seu trabalho). Como conseqüência, os laços em blogs são mais fortes e costumam ser mais ricos em capital social.

a) Suporte Social (relacional e de confiança no ambiente social) - A primeira forma de capital social verificada nos blogs é o suporte. Ao contrário do Orkut, em que pedidos de ajuda, nas comunidades estudadas, são sumariamente ignorados pelos demais, nos blogs o suporte do grupo aos membros acontece com freqüência, como podemos ver no exemplo abaixo:

(...) Será que eu sou tão ruim assim que ninguém quer me empregar? Tá certo que eu não tenho experiência profissional... Só de estágio e olhe lá. Mas se ninguém me der uma chancezinha que for, não vou ter experiência nunca na vida. Droga mesmo. Às vezes essa situação explode na minha cabeça e eu fico chateadíssima. (...).

O post acima é do blog Actea, a Fada de Botas $^{42}$. Relata um problema comum, a busca de um emprego. A dificuldade da autora é imediatamente solidarizada pelos leitores do blog e membros da rede:

é assim de início, dani. mas acho que, mais que currículo, á que se ter per- 
sistência e cara de pau. e bancar a chata. largar o currículo e insistir, mas insistir mesmo. as vezes, mais do que o currículo, os empregadores valorizam o interesse que o candidato demonstra na vaga. não deixa os animos baixarem.

nisia || Dec 06 2004, 09:24 am

É um saco mesmo ter que ficar pedindo dinheiro pro pai e pra mãe, mas um dia isso acaba. Espero que 2005 seja um ano bom pra todo mundo. Abraços e boa sorte! :P

GuiRC $\amalg[w w w]$ Dec 04 2004, 02:15 pm

Tem que meter a cara, ninguem vai vir oferecer emprego, tem que mandar o curriculo pra deus e o mundo. quem for esperto vai perceber que tens muito talento, mana. go girl!

Renata ||[@]_[www]_Dec 03 2004, $\underline{11: 42 \mathrm{pm}}$

Quanto mais fortes os laços, maior o suporte dos membros da comunidade a alguém que passa por dificuldades. Esse suporte, aqui visto sob a forma de mensagens de apoio, pode acontecer também de outras formas. O grupo já registrou ataques de stalkers $^{43}$ e a posterior organização de todos para descobrir quem era e revidar os ataques a um membro. Além disso, o suporte é dado, muitas vezes, sem que exista um pedido mais evidente.

fiz uma promessa de ano novo: não vou mais assistir filme de terror... pelo menos não à noite.... ${ }^{44}$

A mensagem acima relata uma observação da blogueira sam, que é respondida pelos demais membros, com um comentário final da dona do blog:

eu sou igual! eu sou igual! eu fico com medo de levantar do sofá depois de ver filme de terror. tenho pânico!!! uma vez eu assisti um filme (não lembro bem qual) e depois fui na cozinha. quando apaguei a luz pra voltar pra sala, eu tive a nítida sensação de que estava sendo perseguida por "alguma coisa"!! que medo!!!

By Ana Paula, at 2:26 PM

os personagens malditos de o grito me atormentam toda hora que eu deito para dormir. no noite que vi o filme, tive que dormir vendo popeye.

By pirs, at 7:23 PM

LEGAL nao sou a única \o/ a gente devia se reunir um dia e passar a madrugada vendo filmes de terror! e depois desenhos animados! $\backslash \mathrm{o} / \backslash \mathrm{o} / \backslash \mathrm{o} / \backslash \mathrm{o} / \backslash \mathrm{o} / \backslash \mathrm{o} / \backslash \mathrm{o} / \backslash \mathrm{o} / \backslash \mathrm{o} /$ $\backslash \mathrm{o} /$

By sam, at 8:03 PM

A existência de pedidos de suporte indica também uma expectativa de comportamento dos outros membros do grupo. Esse pedido só é colocado porque o blogueiro tem a confiança de que será compreendido e que os demais membros agirão de uma determinada maneira. Neste sentido, representa a constituição de capital social já de segundo nível (confiança no ambiente social), de acordo com a classificação de Bertolini e Bravo (2004).

b) Informação (cognitivo) - Apesar de as informações disponibilizadas nos blogs terem um rápido espraiamento, como as relações de confiança são maiores é possível obtê-las também de forma altamente especializada. Como os blogueiros do grupo em questão possuem as mais diversas especialidades e interesses, é possível encontrar soluções para dúvidas e problemas mais comuns. Um exemplo são os "blogs de pesquisa" 45 surgidos entre os membros do grupo que começaram mestrados e doutorados ou mesmo outros trabalhos de pesquisa. Com os blogs, esses membros começaram a partilhar com a comunidade seus estudos e trabalhos. Além disso, outras informações são disponibilizadas. Um post do blog "dot.dot.dot"46, por exemplo, fez uma análise do lançamento de dois novos browsers, o Firefox 1.0 e o Ópera. Colocando pontos positivos e negativos, o blogueiro 
testou e informou o que pensava dos dois softwares. Nos comentários do mesmo post, é possível observar uma discussão sobre as facilidades dos programas com outro blogueiro, demonstrando o fluxo de conhecimento.

\section{c) Empenho para solucionar os problemas} do grupo (institucional) - Um outro aspecto interessante do capital social da comunidade é o empenho dos membros em construir soluções para as dificuldades da comunidade. Um dos problemas comuns, por exemplo, era a dificuldade de conseguir utilizar os serviços de SMS (envio de mensagens pelo celular). Um dos membros da comunidade construiu um software, chamado Agenda SMS, depois melhorado pelo blogueiro Teivan, dono do blog "JSMS"47, que ampliou o sistema de modo a possibilitar às pessoas enviarem mensagens para várias operadoras de celular de modo gratuito e disponibilizou aos usuários interessados. O sistema difundiu-se rapidamente e foi melhorado pela atuação dos membros da comunidade que relatavam os problemas e solicitavam correções.

Trata-se de um capital institucional porque depende da pré-existência de laços de confiança e reciprocidade, partindo de um capital relacional muito forte. É, evidentemente, capital social de segundo nível, demonstrando maturidade e alto nível de capital social no grupo.

d) Institucionalização das relações (institucional) - Através do fortalecimento dos laços sociais dos blogueiros como um grupo e do fortalecimento dos laços sociais, existe a possibilidade de construção de estruturas sociais mais complexas, como as comunidades virtuais (Recuero, 2002 e 2003). Essas instituições, de acordo com Bertolini e Bravo (2004, online), aumentam o nível de confiança entre os membros da instituição e as redes sociais dos blogs, de forma a ampliar a ação coletiva, além de ampliar a cooperação entre todos.

e) Possibilidade de relacionar-se com pes- soas de mesmos interesses (relacional) - É inegável, em um blog, a possibilidade de conhecer novas pessoas (novos blogueiros) e ampliar o rol de relações através de comentários e leituras de outros blogs, além de interações com seus autores. É, certamente, o capital mais evidente nas redes sociais na Internet.

Percebe-se, na rede estudada, portanto, sinais de interação social mais freqüente, o que demonstra a nítida existência de laços relacionais de forma prioritária. Além disso, a rede estudada demonstra pluralidade e riqueza de capital social, bem como acúmulo e sedimentação (através da presença de capital social de segundo nível). Os laços sociais também demonstram mais força, bem como uma coerência no tempo, gerados, principalmente, através de interação mútua, pelos sistemas de comentários dos blogs. Também percebe-se um maior custo para manter e criar essas relações, já que o blogueiro precisa investir sempre na sua rede social para que continue tendo acesso ao capital do grupo. Um outro fator importante é que um blog, ao contrário de um perfil no Orkut, é dinâmico e necessita de constante investimento de seu dono, também para a manutenção. Talvez por isso tenha maior interação.

\section{Capital Social e Interação nas Redes Sociais na Internet}

A partir do que foi estudado nos casos acima, percebe-se que o capital social constituído no caso do Orkut estaria basicamente nas categorias de "relacional" e "cognitivo" (com a exceção já explicada de alguns aspectos da comunidade "Ciberidea"), de acordo com a classificação de Bertolini e Bravo (2004, online), enquanto o do grupo de blogs estudado compreenderia, além dessas categorias a "confiança no ambiente" (referente à possibilidade de solicitar suporte emocional e na confiança do mesmo por parte dos demais) e "institucional"(no comprometimento com o grupo 
e do surgimento de comunidades). Portanto, já se pode perceber alguma diferença na composição do capital social dos grupos estudados. A que se deve isso?

Inicialmente é importante perceber as diferenças com relação às possibilidades de interação social nos sistemas estudados. Enquanto o sistema do Orkut proporciona várias formas de interação social reativa, ele permite que as redes sejam formadas sem dispêndio de energia para a manutenção dos laços. Uma vez criada a rede, ela se manterá no tempo, independentemente da existência de interação entre os agentes, porque o sistema mantém essa estrutura. Trata-se, portanto, de uma conexão que não perde força com o tempo, o que, em se tratando de relações sociais, demonstra uma certa artificialidade nas estruturas sociais apresentadas. Além disso, no Orkut, como não é necessária a interação na comunidade, muitos dos laços que conectam os indivíduos a elas são meramente associativos (Breiger, 1974), sem que esses indivíduos interajam e, portanto, tenham laços relacionais com os demais. Como conseqüência, há poucos laços relacionais, a maioria, fracos (Granovetter, 1983; Wortley e Wellman, 1990). Com pouca interação e laços fracos, há pouco capital social sendo gerado. Bourdieu explica que o capital social só pode ser compreendido como "being based on indissolubly material and simbolic exchanges" $^{\prime \prime 8}$ (Granovetter, 1983, p. 249) e, sem trocas, ele se torna fluído. Apesar do sistema do Orkut proporcionar, por exemplo, interação mútua no fórum, grande parte da interação, nas comunidades de médio e grande porte (como os casos demonstram) pode ser perdida devido à própria dinâmica da visibilidade social, impedindo que a discussão seja acompanhada, e não gerando resposta. Na rede de blogs, entretanto, os laços são mais fortes e constituem-se principalmente em relacionais. Talvez porque o blogueiro já tenha seu próprio espaço de visibilidade e a interação aconteça de modo descentralizado (não em um único virtual settlement, mas em vários - em todos os blogs das pessoas que participam da rede), a interação seja mais rica e mais social, proporcionando laços mais fortes, relacionais, multiplexos e com mais variedade de capital social acumulado. Quanto mais a parte coletiva do capital social estiver fortalecida, maior a apropriação individual deste capital.

O capital social encontrado nessas redes também demonstrou uma forte conexão com o custo de manutenção dos laços sociais. Nos blogs, onde os laços são espontâneos (no sentido de que não são mantidos pelo sistema, como no Orkut), há mais custo para que eles sejam mantidos. É preciso interagir e interagir várias vezes no tempo. O capital social resultante dessas relações é mais amplo e sedimentado. No Orkut, as conexões são mantidas sem custo para os indivíduos, gerando falta de interesse na participação e baixo capital social. Além disso, o capital é volátil, já que pode ser facilmente retirado (apagado) do grupo ou mesmo influenciado pelos grupos que buscam desestabilizar o sistema e os boatos que confundem os usuários. Nota-se, pois, uma maior confiança relacionada a uma maior profundidade no laço social e, a esta confiança, uma maior capacidade de gerar capital. Essas conclusões vão ao encontro dos trabalhos de Gyarmati e Kyte (2004, pp. 2-10), que explicam, baseados no modelo de formação de Johnson (2003), que o capital social somente pode ser acumulado a partir das conexões ativas (ou seja, aquelas nas quais se investe), enquanto as conexões que não recebem esse investimento implicam depreciação do capital.

O capital social, nas redes do Orkut estudadas, tem também características de primeiro nível, de acordo com a classificação de Bertolini e Bravo (2004), vinculado basicamente ao contato social (Quan-Hasse e Wellman, 2002) (capital relacional) e ao conhecimento e informação (cognitivo). $\mathrm{O}$ capital de primeiro nível, no entender dos autores é central no desenvolvimento do capital social de segundo nível, que demonstra uma maior sedimentação das rela- 
ções sociais. Já nos blogs estudados, encontra-se presente o capital social de segundo nível, que é relacionado com o aspecto coletivo e de grupo. De acordo com Bertolini e Bravo (2004, p. 5), ele possibilita "higher levels of coodination and cooperation" 49 . Enquanto o capital social de primeiro nível estimula o crescimento do capital social de segundo nível, este aumenta o senso de grupo. Apesar do capital social de primeiro nível (conhecimento e informação, relações sociais, suporte) ser comum nos quatro exemplos analisados, as redes sociais no Orkut mostraram-se incapazes de sedimentar essas relações de forma a criar um capital social de segundo nível.

Esse fato poderia levar a um questionamento da capacidade do Orkut em gerar comunidades virtuais, já que esses agrupamentos, por manter um alto nível de cooperação e coesão, possuem igualmente muito capital social tanto de primeiro quanto de segundo níveis. Apesar de funcionarem bastante bem para o estabelecimento de relações sociais, essas parecem não conseguir evoluir nas comunidades estudadas, talvez por conta de sua própria dinâmica, talvez porque sejam transferidas para outros sistemas de interação (como email, ICQ, AIM, MSN, blogs e fotologs, por exemplo) que permitam isso. $\mathrm{O}$ capital social é também, deste modo, associado à densidade de uma determinada rede. Quando mais densa, maior a quantidade de capital gerado pelas relações.

Essa discussão é importante porque muitos estudiosos (vide Castells, 2003; Lévy, 1999, Rheingold, 1994) consideram a comunicação mediada por computador como uma forma de conexão entre as pessoas e aumento do senso de comunidade, através do surgimento de comunidades virtuais. Embora isso possa acontecer, o exemplo do Orkut leva-nos a inferir que possivelmente o surgimento de comunidades dependa, diretamente, da forma através da qual as pessoas utilizam as ferramentas (se de forma relacional ou não), e não apenas de forma individual, mas igual- mente, da apropriação coletiva da tecnologia. A mera existência de um espaço coletivo, ou de uma rede social artificial (pessoas conectadas por um sistema que as mantêm juntas) não garante a existência de laços fortes e, muito menos, a criação de capital social e a sedimentação desse capital entre os envolvidos. Além disso, como explicam Quan-Haase e Wellman (2002, online), o capital social é emergente, ou seja, seu surgimento depende apenas da ação coletiva, não podendo ser determinado externamente pelo sistema ou pelos administradores deste .

\section{Conclusões}

O presente trabalho buscou determinar que tipo de capital social era produzido nas redes sociais de dois sistemas de interação mediada por computador: o Orkut e os weblogs. Definindo o capital social como o conjunto de recursos resultante do conteúdo das trocas sociais na rede, que possui aspectos coletivo e individual de modo simultâneo, ele também é diretamente relacionado à capacidade de interação social de um grupo e de seus laços sociais. Assim, é possível dizer que, nos casos estudados, o sistema de interação mediada por computador proporcionado pelos softwares influencia diretamente no surgimento do capital social desses. No Orkut, há laços associativos (Breiger, 1974), tanto entre os indivíduos quanto entre os indivíduos e as comunidades, criados através de interação reativa (Primo, 1998 e 2003). Esses laços são mantidos pelo sistema sem custo para os envolvidos, que não precisam interagir socialmente se não desejarem. Como conseqüência, o capital social das redes torna-se, justamente, a possibilidade de fazer parte dessas redes, mais do que informação (que também está presente, como demonstra a comunidade "Ciberidea", mas de maneira mais difusa e, possivelmente, ancorada em outros virtual settlements - outros espaços de interação- que proporcionam um aprofun- 
damento dos laços). Na rede de blogs há laços relacionais (Breiger, 1974), que necessitam de manutenção e investimento. O sistema aqui, não mantém os laços artificialmente. Como resultado, é possível encontrar capital social já sedimentado (de segundo nível) (Bertolini e Bravo, 2004), através de instituições e grupos fortes e mais densos do que os estudados no Orkut, além de maior variedade e qualidade.

Essas diferenças podem ter influência no surgimento de comunidades virtuais (Quan-Haase e Wellman, 2002, online; Wellman e Wortley, 1990), prejudicando diretamente a dinâmica de evolução da rede social, tanto nos seus aspectos de crescimento, quando na sua dinâmica de formação. Ora, tomando o capital social como um indicativo da densidade da rede (e, por conseqüência, da existência de grupos e comunidade - Wellman, 1997, Bertolini e Bravo, 2004), o sistema do Orkut pareceria ser incapaz de sedimentar laços sociais, de forma a acumular, igualmente, capital social, e torná-lo institucionalizado.

Por fim, gostaríamos de salientar que os apontamentos levantados neste estudo são resultado de três casos específicos, e, portanto, são conclusões limitadas, que não podem ser generalizadas de modo total, sob pena da perda da variedade e da riqueza da sociabilidade no ciberespaço. Outros estudos, que abranjam grupos maiores ou menores de forma mais específica podem auxiliar a dirimir as questões levantadas neste trabalho •

\section{Notas}

Agradecimentos: A autora gostaria de agradecer a Alex Primo, Érico Assis e Ricardo Araújo pelas leituras, observações, debates e contribuições no sentido de aperfeiçoar, aclarar e melhorar as idéias contidas neste trabalho.

1 Apesar de uma grande parte dessa abordagem ser voltada para a Sociometria, uma forma matemática de investigação das redes sociais, neste trabalho o estudo de redes sociais nos interessa não como método, mas como metáfora para discutir a constituição do capital social nos grupos formados via comunicação mediada por computador e a importância da interação social neste.

2 Tradução da autora: "os indivíduos não podem ser estudados independentemente de suas relações com os outros, nem podem as díades ser isoladas de suas estruturas afiliadas".

3 Tradução da autora: "estabelece uma conexão entre um par de atores".

4 A interação social nessa abordagem, tem seus fundamentos no interacionismo simbólico, onde a interação é uma "ação social caracterizada por uma orientação meramente recíproca". As relações sociais, em tal visão, não são vistas como elementos finalizados, "fechados", mas como algo "aberto e subordinado ao reconhecimento contínuo por parte dos membros da comunidade" (Joas, 1996, p. 130).

5 Tradução da autora: "a força de um laço é uma combinação (provavelmente linear) da quantidade de tempo, intensidade emocional, intimidade (confiança mútua) e serviços recíprocos que caracterizam um laço".

6 Laços fortes e fracos são uma denominação reducionista, embora popular. Isso porque nos levam a acreditar que um determinado laço seria sempre forte ou fraco, quando na realidade, dependendo do tempo e da quantidade de interação investida na conexão, um laço pode ter diferentes gradações.

7 Tradução da autora: "refere-se à conexão entre indivíduos - redes sociais e normas de reciprocidade e confiança que emergem dela".

8 Tradução da autora: "0 capital social é o agregado dos recursos atuais e potenciais os quais estão conectados com a posse de uma rede durável, de relações de conhecimento e reconhecimento mais ou menos institucionalizadas, ou em outras palavras, à associação a um grupo - 0 qual provê cada um dos membros com 0 suporte do capital coletivo (...)".

9 Para Bourdieu, o capital social é também referenta ao campo de atuação (social). Outras formas de capital (econômico e cultural) seriam relacionadas a outros campos de atuação do indivíduo. Entretanto, o capital social 
pode ser convertido em outras formas de capital, como capital econômico, de acordo com as ações do grupo (1983, p. 249).

10 Tradução da autora: "A rede de relações é o produto das estratégias de investimento, individuais ou coletivas, conscientes ou inconscientes, que objetivam estabelecer ou reproduzir relações sociais que são diretamente utilizáveis em um curto ou longo espaço de tempo".

11 Tradução da autora: "as conexões individuais em uma rede social podem também variar em sua habilidade de acumular capital social, baseada em quão bem os indivíduos interagem".

12 http://www.orkut.com

130 termo "comunidade" aqui é usado sem a acepção teórica de comunidade virtual. Isso porque, como será explicado adiante no trabalho, não acreditamos que essas estejam presentes no Orkut. Trata-se, unicamente, de usar o termo através do qual o próprio sistema identifica esses grupos.

14 A classificação da interação mediada por computador proposta por Primo $(1998,2003)$ nos é muito útil para que se perceba que mesmo a interação reativa pode ser social em um software como o Orkut. Para o autor, a interação reativa apresenta-se como uma situação de estímulo-resposta, onde não há espaço para a criação e a transformação daqueles envolvidos no processo. Já a interação mútua é aquela em que existe negociação, troca e modificação dos agentes envolvidos, já que ambos participam ativamente da construção das trocas comunicativas. Trata-se de uma visão que contribui para 0 estudo porque trabalha fundamentalmente com a mediação pelo computador.

15 A comunidade foi criada pela autora do texto, com 0 objetivo de estudar e tentar compreender como se dá 0 processo de criação e manutenção das redes sociais no sistema. A autora procurou interferir minimamente no processo, deixando as pessoas livres para interagir como desejassem, apesar de ser a moderadora.

16 A interação no Orkut, como foi explicado, se dá sob a forma de fórum. Cada tópico é um novo espaço de interação, que é preenchido com manifestações sobre 0 assunto dos associados à comunidade (posts).
17 http://www.orkut.comCommMsgs.aspx?cmm=33185\&tid=6001724

18 http://www.orkut.com/CommMsgs.aspx?cmm=33185\&tid=1

19 http://www.orkut.om/CommMsgsaspx?cmm=33185\&tid=5198370

20 http://www.orkut.om/CommMsgs.aspx?cmm=33185\&tid=5198370

$21 \mathrm{http://www.orkut.com/CommMsgs.aspx?cmm=33185 \& tid=6001724}$

22 http://www.orkut.om/CommMsgsaspx?cmm=33185\&tid=5161326

23 http:/ / www.orkut.com/Community.aspx?cmm=154291

24 Dados de cinco de janeiro de 2005.

$25 \mathrm{http}: / /$ www.orkut.om/CommMsgsaspx?cmm=154291\&tid=622955

26 Até 0 dia 10 de janeiro de 2005.

27 Segundo o entendimento de Jones (1997), trata-se de um espaço que proporciona a interação social e, como conseqüência, o surgimento de comunidades virtuais.

28 Embora pudesse ser discutida a possibilidade da existência de capital social de segundo nível (institucional) na comunidade, que estaria associado ao grupo de pesquisa, o mesmo não é evidente no Orkut e por isso, não está sendo relacionado neste trabalho.

$29 \mathrm{http}: / /$ www.orkut.com/Community.aspx? $\mathrm{cmm}=47646$

30 Dados do dia 10 de janeiro de 2005.

31 Dados do dis 10 de janeiro de 2005.

32 http://www.orkut.om/CommMsgsaspx?cmm=47646\&tid=4473898

$33 \mathrm{http}: / /$ www.orkut.om/CommMsgsaspx?cmm=47646\&tid=5556714

34 http://www.orkut.om/CommMsgssaspx?cmm=47646\&tid=4473898

35 http://www.orkut.om/CommMsgsaspx?cmm=47646\&tid=2735993

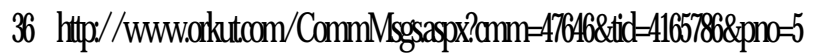

$37 \mathrm{http:} / /$ www.orkutcom/CommMsgasapx?mm=47646\&tid=473398\&pno=3

38 Grupos que se dedicam a abrir o maior número de tópi- 
cos o possível para dificultar o fluxo de informações da comunidade ou mesmo em perfis, ou seja, a criar uma forma de "flood". Como exemplos, estão as comunidades "Só Multiplicadores"<http://www.orkut.com/ Community.aspx?cmm=1034595>, "Central dos Multiplicadores" $<$ http: / / www.orkut.com/ Community.aspx?cmm=810454> e "Multiplicadores S/ A" <http://www.orkut.com Community.aspx?cmm=1076712>.

39 Recentemente, um episódio sobre o roubo de comunidades no sistema ilustrou a falta de confiança nas informações divulgadas nas comunidade. Apesar dos usuários "roubados" manifestarem-se efusivamente sobre 0 ocorrido, a maioria dos demais não deu qualquer crédito, e 0 caos foi instaurado. Mais sobre 0 assunto pode ser conferido no resumo publicado aqui <http:// www.gardenal.org/inagaki/archives/2005/01/ a_verdade_sobre.html>.

40 O grupo possuía um weblog coletivo, que perdeu a força <http://blogueirospel.blogspot.com/>. Entretanto, a rede continua existindo, como se pode observar a partir desta análise.

41 Vide Recuero $(2002,2003)$.

42 http://www.actea.blogspot.com/2004_12_01_actea_archive.html

43 Stalker é um perseguidor, que usa o weblog para desmerecer o blogueiro. Para maiores detalhes, vide Recuero, 2002.

44 http://ashtray_girl.blogspot.com/2005/01/fiz-umapromessa-de-ano-novo-no-vou.html

45 Como exemplo, podemos citar os blogs "Um blog de Pesquisa"<http://www.pontomidia.com.br/ricardo/ p e s quis a / >, "Rod a pé " < h t t p: / / www.pontomidia.com.br/erico/rodape/> e "Outro blog de Pesquisa" $<$ http://www.outroblogdepesquisa.blogspot.com/>.

46 http://www.pontomidia.com.br/ricardo/arquivos/ 001965.html

\section{7 http://jsms.blogspot.com/}

48 Tradução: "sendo baseado em trocas indissoluvelmente materiais e simbólicas". Grifo nosso.
49 Tradução da autora: "níveis mais altos de coordenação e cooperação".

\section{Referências}

BARABÁSI, Albert. Linked. How Everything is Connected to Everything else and What it means for Business, Science and Everydai Life. Cambridge: Plume, 2003.

BERTOLINI, Sandra e BRAVO, Giácomo. Social Capital, a Multidimensional Concept. Disponível em <http:// www.ex.ac.uk/shipss/politics/research/socialcapital/ other/bertolini.pdf> Acesso em 17/10/2004.

BOURDIEU, Pierre. The Forms of Capital. Originalmente publicado em "Ökonomisches Kapital, kulturelles Kapital, soziales Kapital" in Soziale Ungleichheiten (Soziale Welt, Sonderheft 2). (pp. 248-257) Tradução de Richard Nice. Disponível online em <http:// www.pontomidia.com.br/raquel/resources/03.html>. Acesso em 15/07/2004.

CASTELLS, Manuel. A Galáxia da Internet. Rio de Janeiro: Jorge Zahar editora, 2003.

DEGENNE, Alain e FORSÉ, Michel. Introducing Social Networks. London: Sage, 1999.

EFIMOVA, Lilia. What is "beneath your current threshold"? Social visibility in persistent conversations <https://doc.telin.nl/ dscgi/ds.py/ViewProps/File-47362>. Trabalho apresentado no Persistent Conversations Workshop, no HICSS TUTORIAL DAY, em 03 de Janeiro de 2005.

FLORA, Jan L. Social Capital and Communities of Place. In: Rural Sociology, 63., 1998. p. 481-506. Disponível em < http://poverty.worldbank.org/files/4183_flora1.pdf>. Acesso em 05/04/2004.

GARTON, Laura; HARTHORNTHWAITE, Caroline; WELLMAN, Barry. Studying Online Social Networks. Journal of Computer Mediated Communication, V 3, issue 1 (1997). Disponível em <http://www.ascusc.org/jcmc/ vol3/issuel/garton.html>. Acesso em 12/04/2004.

GYARMATI, David e KYTE, Darrel. Social Capital, Network Formation and the Community Employment Innovation Project. In: Policy Research Iniciative, Volume 6, Number 3. 
Disponível em <http://policyresearch.gc.ca/ page.asp?pagenm=v6n3_art_05>. Acesso em 04/05/2004.

GRANOVETTER, Mark. The Strength of Weak Ties. In: The American Journal of Sociology, Vol. 78, No. 6, Maio de 1973. pp 1360-1380.

JOAS, Hans. O Interacionismo Simbólico. (pp. 126-174) In: GIDDENS, Anthony e TURNER, Jonathan. Teoria Social Hoje. São Paulo: Editora da UNESP, 1996.

JONES, Quentin. Virtual-Communities, Virtual Settlements \&Cyber-Archaeology:A Theoretical Outline. In: Journal of Computer Mediated-Communication, V. 3, número 3. Dezembro de 1997. Disponível em < http://www.ascusc.org/

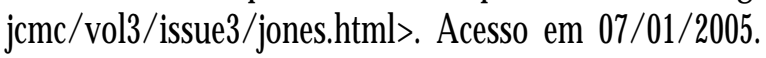

LÉVY, Pierre. Cibercultura. São Paulo: Ed. 34, 1999.

MARLOW, Cameron. Audience, structure and authority in the weblog community. Trabalho apresentado na International Communication Association Conference em New Orleans, 2004. Disponível em <http://overstated.net/ media/ICA2004.pdf>

PUTNAM, Robert D. Bowling Alone. The collapse and Revival of American Community. New York: Simon e Schuster, 2000.

PRIMO, Alex. Interação Mútua e Interação Reativa: Uma proposta de Estudo. Trabalho apresentado no XXI Congresso da Intercom em setembro de 1998. Recife, PE. Disponível em <http://usr.psico.ufrgs.br/ aprimo/pb/ intera.htm>. Acesso em 06/01/2005.

- Interação Mediada por Computador: a comunicação e a educação a distância segundo uma perspectiva sistêmicorelacional. Tese de Doutorado. Apresentada ao Programa de Pós-Graduação em Informática na Educação em março de 2003.

PRIMO, Alex e RECUERO, Raquel. Hipertexto Cooperativo: Uma análise da escrita coletiva a partir dos blogs e da wikipedia. In: Revista Famecos, Porto Alegre, v. 22, p. 5465, 2003.

QUAN-HAASE, Anabel e WELLMAN, Barry. How does the Internet Affect Social Capital. In: HUYSMAN, Marleen e WULF, Volker (org.). IT and Social Capital. Novembro de 2002. Disponível em <http:// www.chass.utoronto.ca/ wellman/publications / internetsocialcapital/Net_SC-09.PDF>. Acesso em 05/ $01 / 2005$.

RECUERO, Raquel da Cunha. Teoria das Redes e Redes Sociais na Internet. Trabalho apresentado no XXVII INTERCOM, na PUC/RS em Porto Alegre. Setembro de 2004.

Weblogs, Webrings e Comunidades Virtuais. In: Revista 404notfound - Revista Eletrônica do Grupo Ciberpesquisa. Edição 31, agosto de 2003. Disponivel em <http:/ /www.facom.ufba.br/ ciberpesquisa/404nOtFOund/404_31.htm>

Webrings: As Redes de Sociabilidade e os Weblogs. In: Sessões do Imaginário, Famecos/PUCRS. 2004

RHEINGOLD, Howard. La Comunidad Virtual: Una Sociedad sin Fronteras. Gedisa Editorial. Colección Limites de La Ciência. Barcelona, 1994.

SHKLOVSKI, Irina, KIESLER, Sara e KRAUTZ, Robert. The Internet and Social Interaction: A Meta- analysis and Critique of studies, 1995-2003. Carnegie Mellon University. Disponível em http://www-2.cs.cmu.edu/ kraut/ RKraut.site.files/articles / Shklovski04InternetUseSocialRleationships-meta-analysis.pdf. Acesso em 20/12/2004.

SCOTT, John. Social Network Analysis. A Handbook. London UK: Sage Publications, 2000. Second Edition.

TINDALL, D. B; WELLMAN, Barry. Canada as Social Structure: Social Network Analysis and Canadian Sociology. Journal of Canadian Sociology, 2001. Disponível em <http:/ / www.chass.utoronto.ca/ wellman/ publications/cansocstr/Can_Net-Final-30Ap01.htm>. Acesso em 22/03/2004.

TÖNIES, Ferdinand. Comunidade e Sociedade. Textos Selecionados. In: MIRANDA, Orlando. Para Ler Ferdinand Tönies. São Paulo: Edusp,1995.

WASSERMAN, Stanley e FAUST, Katherine. Social Network Analysis. Methods and Applications. Cambridge, UK: Cambridge University Press, 1994.

WATZLAVICK, Paul, BEAVIN, Janet e JACKSON, Don. Pragmática da Comunicação Humana. São Paulo: Cultrix, 2000. $11^{\mathrm{a}}$. edição. 
WEBER, Max. Conceitos Básicos de Sociologia. São Paulo: Editora Moraes, 1987.

WELLMAN, Barry et. al. The Social Affordances of Internet for Networked Individualism. In: Journal of computer Mediated Communication, V. 8 Issue 3, (2003). Disponível em <http://www.ascusc.org/jcmc/vol8/issue3/ wellman.html>. Acesso em 23/03/2004.

WELLMAN, Barry. Physical Place and CyberPlace: The Rise of Personalized Networking. Fevereiro de 2001. Disponível em: $<$ http://www.chass.utoronto.ca/ wellman/publications/ individualism/ijurr3a1.htm>. Acesso em abril de 2004.

_.. Structural Analysis: From Method and Metaphor to Theory and Substance. Publicado em: WELLMAN, Barry e BERKOWITZ, S. D. editores. Social Structures: A Network Approach. Cambridge: Cambridge University Press, 1988.

- An Electronic Group is Virtually a Social Network. In KIESLER, Sarah (org.) Culture of Internet. Hilsdale, NJ: Lawrence Erlbaum, 1997. (pp. 179-205).

WORTLEY, Scott e WELLMAN, Barry. "Different Strokes from Different Folks: Community Ties and Social Support" In: American Journal of Sociology 96, Nov., 1990: 558-88. 